\title{
Concentrations of plasma atrial natriuretic factor during and after reversion of ventricular tachycardia
}

\author{
Nicholas Twidale, John R Oliver, Margaret Menadue, Andrew M Tonkin
}

\begin{abstract}
Plasma concentrations of immunoreactive atrial natriuretic factor were considerably increased (mean 745 (376) $\mathrm{pg} / \mathrm{ml}$ ) in 15 patients during spontaneous ventricular tachycardia. There was no significant relation, however, between concentrations of plasma atrial natriuretic factor and systolic arterial blood pressure during tachycardia. Samples taken 30 minutes and 24 hours after reversion of ventricular tachycardia to sinus rhythm showed that, although plasma concentrations of atrial natriuretic factor had fallen significantly, they were still raised after 24 hours. Raised concentrations of atrial natriuretic factor during ventricular tachycardia did not seem to contribute significantly to the hypotension that is often associated with the arrhythmia.
\end{abstract}

Mammalian atrial tissue has been shown to contain secretory-like storage granules with characteristics similar to those of endocrine peptide secretory cells. ${ }^{12}$ These granules contain a polypeptide hormone, which is first synthesised as a 151 amino acid prohormone. ${ }^{34}$ The prohormone is further processed to several smaller peptides, one of which is $\alpha$ natriuretic polypeptide, or atrial natriuretic factor, a 28 amino acid polypeptide with potent natriuretic and diuretic properties. ${ }^{56}$

A considerable body of evidence suggests that atrial natriuretic factor may help maintain sodium ion and water balance and modulate the renin-angiotensin-aldosterone system. ${ }^{7}$ In addition, a moderate vasodilatory effect has been reported after infusion of atrial natriuretic factor in humans. ${ }^{8}$ The major stimulus for release of atrial natriuretic factor into the blood stream is atrial distension, as occurs in congestive cardiac failure, although recent studies suggest that atrial natriuretic factor released from abnormal ventricular myocardium, may also contribute. ${ }^{910}$

Plasma concentrations of atrial natriuretic factor are raised in patients with supraventricular tachycardias, but they also seem to rise during ventricular tachycardia; however, fewer patients with this arrhythmia have been studied. ${ }^{11} 12$ Because patients with ventricular tachycardia often have severe ventricular dysfunction, atrial natriuretic factor concentrations may be extremely high, owing to combined atrial natriuretic factor release from atrial and ventricular sites. The aim of this study was to examine the pattern of atrial natriuretic factor release during ventricular tachycardia, and evaluate whether this can contribute appreciably to the haemodynamic changes after the onset of tachycardia.

\section{Patients and methods \\ PATIENTS}

This study was carried out within the guidelines set down by the National Health and Medical Research Council of Australia and was approved by the hospital human ethics committee.

We studied 15 male patients (mean age $68 \cdot 2$ (8.9 years)), who had presented with spontaneous sustained ventricular tachycardia that was remote from ( $>1$ week) acute myocardial infarction. All patients had had at least one documented myocardial infarction, and seven patients had coronary artery disease confirmed by coronary angiography. Ventricular tachycardia was diagnosed by 12 lead electrocardiography recorded at a standard speed $(25 \mathrm{~mm} / \mathrm{s})$ and amplitude $(1 \mathrm{mV} / \mathrm{cm})$. Multichannel simultaneous recordings were obtained in all cases. The electrocardiograms were reviewed by two experienced electrocardiographers and the following diagnostic criteria for ventricular tachycardia were applied in each case: $(a)$ sustained wide QRS $(>0.12 \mathrm{~s})$ tachycardia ( $>100$ beats $/ \mathrm{min}$ ); $(b)$ presence of atrioventricular dissociation; $(c)$ typical QRS configuration in V1 and V6 as described by Wellens et al. ${ }^{13}$

Ventricular tachycardia was confirmed by transoesophageal electrocardiography in two patients and by electrophysiology study in another seven patients.

Patients were interviewed and the duration of ventricular tachycardia determined. Systolic arterial blood pressure was measured indirectly by a bladder cuff sphygmomanometer and a blood sample was taken after insertion of a peripheral intravenous line and before attempted reversion. Two subsequent samples were taken 30 minutes and 24 hours after reversion to sinus rhythm.

All patients had chronic ischaemic heart disease, and left ventricular function was assessed by radionuclide ventriculography. ${ }^{14}$ In addition, $M$ mode echocardiograms were recorded by a Diasonics DRF 400 with a 3.5 or $5 \mathrm{MHz}$ transducer to measure left atrial diameter 24 hours after reversion to sinus rhythm. Patients were studied in the left semilateral position, and recordings were taken 
Plasma concentrations (mean $S D$ ) of atrial natriuretic factor ( $A N F$ ) $(1 \mathrm{pg} / \mathrm{ml}=0.325 \mathrm{pmol} / \mathrm{l})$ before, and 30 minutes and 24 hours after reversion in 15 patients with ventricular tachycardia. The normal range is also shown.

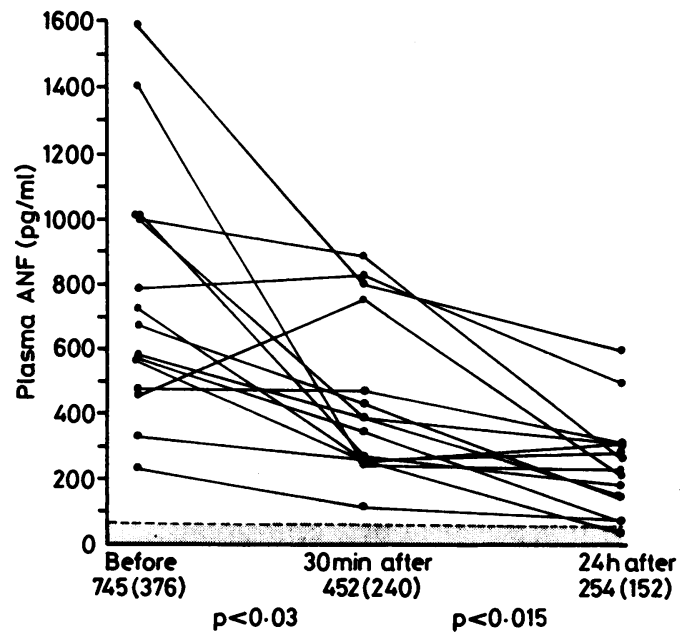

from the parasternal long axis view at the level of the aortic root. ${ }^{15}$

Thirteen patients were receiving concomitant medication when they were studied. This included an antiarrhythmic drug in nine, diuretic in six, calcium channel blocker in three, angiotensin converting enzyme inhibitor in two, and $\beta$ blocking agent in one patient. Finally, renal function was assessed; plasma creatinine concentrations were within the normal range $(0.06-0.12 \mathrm{mmol} / \mathrm{l})$ in all but three patients $(0 \cdot 3,0 \cdot 15$, and $0 \cdot 14 \mathrm{mmol} / \mathrm{l})$.

\section{BLOOD COLLECTION AND RADIOIMMUNOASSAY} OF ATRIAL NATRIURETIC FACTOR IN PLASMA

Venous blood $(10 \mathrm{ml})$ was obtained via the antecubital vein and collected into a chilled tube containing EDTA and aprotinin (10 000 units; Bayer, Australia). Plasma was separated immediately by centrifugation, snap frozen, and stored at $-20^{\circ} \mathrm{C}$ until assay. Plasma was extracted and atrial natriuretic factor concentration was determined by radioiummunoassay under non-equilibrium conditions at $4^{\circ} \mathrm{C}$. The method has been previously described in detail elsewhere. ${ }^{11}$

\section{CONCENTRATIONS OF ATRIAL NATRIURETIC} FACTOR IN CONTROLS

Atrial natriuretic factor was measured in blood samples from 34 normotensive healthy volunteers ( 14 male, 20 female) with normal dietary intake of sodium and normal electrolytes. The upper and lower limits of the normal range were $70 \mathrm{pg} / \mathrm{ml}$ and $4 \mathrm{pg} / \mathrm{ml}$ and no sex dependent differences were found (men 36 (14) pg/ $\mathrm{ml}$, women 33 (16) pg/ml (mean (SD)).

\section{Results}

The figure shows plasma concentrations of atrial natriuretic factor before and after reversion to sinus rhythm in the 15 patients with spontaneous ventricular tachycardia. During ventricular tachycardia, all patients had atrial natriuretic factor concentrations well above the upper limit of normal in this laboratory $(70 \mathrm{pg} /$ $\mathrm{ml}$ ). The table shows that ventricular tachycardia was reverted to sinus rhythm by brief overdrive pacing (usually 5-10 seconds ventricular pacing at a rate $10-20$ beats/min faster than the ventricular tachycardia rate) in five patients, DC cardioversion after intravenous midazolam sedation in four patients, intravenous amiodarone $(350 \mathrm{mg})$ in three patients, intravenous lignocaine (100 $\mathrm{mg})$ in two patients, and intravenous sotalol $(120 \mathrm{mg})$ in one patient. In 13 patients concentrations of plasma atrial natriuretic factor fell 30 minutes after reversion, but not to within the normal range in any patient. In two patients plasma atrial natriuretic factor concentrations increased; one was treated with intravenous amiodarone and the other by overdrive ventricular pacing. The mean concentration of plasma atrial natriuretic factor was 745 (376) $\mathrm{pg} / \mathrm{ml}$ before reversion and $452(240) \mathrm{pg} / \mathrm{ml} 30$ minutes after reversion ( $\mathrm{p}<0.03$ by Student's paired $t$ test). The fall in concentration of atrial natriuretic factor was apparently independent of the mode of reversion of ventricular tachycardia. After 24 hours, the mean concentration of plasma atrial natriuretic factor had fallen further to $254(152) \mathrm{pg} / \mathrm{ml}(\mathrm{p}<0.015)$ but was still raised, and only one patient was within the normal range. This contrasts with findings in a previous group of 23 patients with supraventricular tachycardia reported from this laboratory. ${ }^{11}$ Among this group of patients, plasma atrial natriuretic factor concentrations fell from a mean of 256 (43) pg/ml during supraventricular tachycardia to a mean of 120 (19) $\mathrm{pg} / \mathrm{ml}$ within 30 minutes of reversion, with levels in five patients falling to within the normal range.

Relation between clinical findings, method $(s)$ of reversion of ventricular tachycardia, and plasma atrial natriuretic factor concentrations

\begin{tabular}{|c|c|c|c|c|c|c|c|c|c|c|c|}
\hline \multirow{2}{*}{$\begin{array}{l}\text { Case } \\
\text { No }\end{array}$} & \multirow[b]{2}{*}{$S H D$} & \multirow[b]{2}{*}{ Drug } & \multirow{2}{*}{$\begin{array}{l}E F \\
\left({ }_{0}^{o}\right)\end{array}$} & \multirow{2}{*}{$\begin{array}{l}L A D \\
(m m)\end{array}$} & \multirow{2}{*}{$\begin{array}{l}V T \\
\text { (beats/min) }\end{array}$} & \multirow{2}{*}{$\begin{array}{l}\text { Duration } \\
\text { (min) }\end{array}$} & \multirow{2}{*}{$\begin{array}{l}B P \\
(m m H g)\end{array}$} & \multirow[b]{2}{*}{ Reversion } & \multicolumn{3}{|c|}{$A N F(p g / m l)$} \\
\hline & & & & & & & & & During & $30 \mathrm{~min}$ & 24 hours \\
\hline 1 & CAD & $D / A$ & 31 & 60 & 150 & 120 & 140 & DC & 330 & 263 & 290 \\
\hline 2 & CAD-An & $\mathrm{D} / \mathrm{C}$ & 15 & 45 & 145 & 15 & 135 & $\mathrm{Am}$ & 792 & 833 & 500 \\
\hline 3 & CAD & A & 51 & 50 & 150 & 200 & 90 & Pace & 475 & 475 & 318 \\
\hline 4 & CAD & & 30 & 35 & 190 & 35 & 90 & Pace & 1000 & 394 & 150 \\
\hline 5 & CAD & D/A/Cá & 43 & 29 & 150 & 130 & 140 & Pace & 567 & 350 & 81 \\
\hline 6 & CAD & & 43 & - & 160 & 10 & 100 & Pace & 675 & 439 & 149 \\
\hline 7 & CAD-An & A & 56 & 40 & 200 & 90 & 70 & DC & 723 & 257 & 47 \\
\hline 8 & CAD & & 37 & 42 & 120 & 10 & 160 & Lig & 574 & 375 & 318 \\
\hline 9 & CAD-An & A/Cá & 37 & 46 & 150 & 60 & 90 & Lig & 1000 & 891 & 270 \\
\hline 10 & CAD & - & 47 & 41 & 160 & 90 & 140 & Pace & 790 & 270 & 189 \\
\hline 11 & CAD & $\mathrm{D} / \mathrm{A} / \mathrm{C}$ & 15 & - & 210 & 5 & 120 & $\mathrm{Am}$ & 459 & 758 & 223 \\
\hline 12 & CAD-An & Cá & 24 & 37 & 180 & 18 & 110 & Sot & 1409 & 245 & 236 \\
\hline 13 & CAD & & 43 & 45 & 130 & 200 & 100 & DC & 559 & 254 & 350 \\
\hline 14 & CAD-An & D/A & 27 & - & 200 & 5 & 140 & $\mathrm{Am}$ & 236 & 115 & 91 \\
\hline 15 & CAD & D & 25 & 45 & 170 & 60 & 90 & DC & 1591 & 810 & 600 \\
\hline
\end{tabular}

SHD, structural heart disease; EF, ejection fraction; LAD, left atrial dimension; VT, ventricular tachycardia; BP, systolic arterial blood pressure; ANF, atria natriuretic factor; CAD, coronary artery disease; An, left ventricular aneurysm; DC, direct current cardioversion; Am, amiodarone; Pace, overdrive pacing; Lig, lignocaine; Sot, sotalol; D, diuretic; $A$, antiarrhythmic drug; $C$, angiotensin converting enzyme inhibitor; Cá, calcium blocker; $\beta, \beta$ blocker. 
The duration of spontaneous ventricular tachycardia (mean (SD) 69.9 (67) minutes) had no apparent effect on plasma atrial natriuretic factor concentrations; two patients had raised plasma atrial natriuretic factor concentrations ( 236 and $459 \mathrm{pg} / \mathrm{ml}$ ) with ventricular tachycardia lasting only five minutes. Similarly, the rate of ventricular tachycardia (mean cycle length $374(58) \mathrm{ms}$ ) did not seem to influence plasma atrial natriuretic factor concentrations.

There seemed to be a weak inverse relation between plasma atrial natriuretic factor concentrations during ventricular tachycardia and systolic arterial blood pressure, but this was not statistically significant $(r=-0.3 ; p=0.11$ by Spearman's test).

All patients had chronic ischaemic heart disease with a mean left ventricular ejection fraction of $34.9(12.4) \%$. In 12 patients the ejection fraction was $<45 \%$, but this measurement had no apparent influence on plasma atrial natriuretic factor concentrations during and 30 minutes after reversion of ventricular tachycardia. Furthermore, there was only a weak non-significant inverse relation between the ejection fraction and atrial natriuretic factor concentrations measured at 24 hours after reversion to sinus rhythm ( $\mathrm{r}=$ $-0.3 ; p=0 \cdot 11$ ).

Finally, mean left atrial dimension measured 24 hours after reversion to sinus rhythm by $M$ mode echocardiography was $43.8(7 \cdot 7) \mathrm{mm}$; it was $>40 \mathrm{~mm}$ in eight patients.

\section{Discussion}

Our results show that patients with spontaneous ventricular tachycardia have considerably higher plasma concentrations of atrial natriuretic factor than healthy controls. These results are consistent with earlier studies of smaller numbers of patients and studies in which ventricular tachycardia was induced during programmed ventricular stimulation or simulated by rapid ventricular pacing. ${ }^{1216-19}$ Given that atrial natriuretic factor has natriuretic and diuretic properties that are potentially beneficial in patients with ventricular tachycardia, the increase may account for the polyuria that is occasionally reported in these patients. ${ }^{2021}$ Although polyuria was not reported by any of our patients, this may be because other neurohormonal reflexes were stimulated by the decreased cardiac output during ventricular tachycardia. These include activation of the sympathetic and renin-angiotensinaldosterone systems, which would favour oliguria. ${ }^{1622}$ Similarly, the vasodilatory action of atrial natriuretic factor may have been modified by stimulation of catecholamines and vasopressin release during ventricular tachycardia. $^{16}$

Plasma concentrations of atrial natriuretic factor seem to rise as early as five minutes after the onset of ventricular tachycardia and remain raised during prolonged periods of tachycardia, apparently independently of the severity of underlying left ventricular dysfunction or rate of ventricular tachycardia. Because atrial dimension, pressure and rate were not routinely measured during ventricular tachycardia, we cannot comment on the possible influen$\mathrm{ce}(\mathrm{s})$ of these variables on atrial natriuretic factor release. Increases in left atrial dimension measured by $M$ mode echocardiography, however, were reported within minutes after the onset of induced ventricular tachycardia. ${ }^{16}$ After reversion of ventricular tachycardia, plasma concentrations of atrial natriuretic factor fell slowly and were still significantly raised 24 hours after reversion to sinus rhythm. This may be explained by impaired renal clearance of atrial natriuretic factor in our patients who generally had poor left ventricular function with reduced cardiac output. In addition, left atrial dimension remained increased in eight patients, and continued atrial natriuretic factor release might also contribute to high postreversion plasma atrial natriuretic factor concentrations.

Spontaneous ventricular tachycardia is associated with considerably raised concentrations of plasma atrial natriuretic factor which fall slowly and apparently independently of the mode of reversion whether this is pharmacological or non-pharmacological.

NT is supported by a postgraduate research fellowship from the National Health and Medical Research Council of Australia.

1 Jamieson JD, Palade GE. Specific granules in the atrial muscle cells. J Cell Biol 1964;23:151-72.

2 de Bold AJ, Raymond J, Benescome SA. Atrial specific granules of the rat heart, light microscopic staining and histochemical reaction. J Histochem Cytochem 1978;26: 1094-102.

3 Oikawa S, Imai M, Veno A, et al. Cloning and sequence analysis of cDNA encoding a precursor for human atrial natriuretic polypeptide. Nature 1984;309:724-6.

4 Lewicki J, Greenberg B, Yamanaka M, et al. Cloning, sequence analysis and processing of the rat and human atrial natriuretic peptide precursors. Fed Proc 1986; 45:2086-90.

5 de Bold AJ, Borenstein HB, Veress AT, Sonnenberg HA. A rapid and potent natriuretic response to intravenous 1981;28:89-94.

6 Kuribayashi T, Nakazato $M$, Tanaka $M$, et al. Renal effects of human-atrial natriuretic polypeptide. $N$ Engl J Med of human-atrial natr.

7 Laragh JH. Atrial natriuretic hormone, the reninaldosterone axis, and blood pressure-electrolyte homeostasis. N Engl J Med 1985;312:1330-40.

8 Bolli P, Muller FB, Linder L, et al. The vasodilator potency of atrial natriuretic peptide in man. Circulation 1987;75: 221-8.

9 Franch HA, Dixon RAF, Blaine EH, Siegl PKS. Ventricular atrial natriuretic factor in the cardiomyopathic hamster model of congestive cardiac failure. Circ Res 1988;62: $31-6$.

10 Edwards BS, Ackerman DM, Lee ME, Reeder GS, Wold $\mathrm{LE}$, Burnett JC. Identification of atrial natriuretic factor within ventricular tissue in hamsters and humans with congestive heart failure. J Clin Invest 1988;81:82-6.

11 Oliver JR, Twidale N, Lakin C, Cain M, Tonkin AM. Plasma atrial natriuretic polypeptide concentrations during and after reversion of paroxysmal supraventricular ing and after reversion of paroxysmal supr
tachycardias. Br Heart $J$ 1988;59:458-62.

12 Crozier IG, Ikram H, Nicholls MG, Espiner EA, Yandle TG. Atrial natriuretic peptide in spontaneous tachycardias. Br Heart J 1987;58:96-100.

13 Wellens HJJ, Bar FWHM, Lie KI. The value of the electrocardiogram in the differential diagnosis of a tachycardia with a widened QRS complex. $A m$ J Med 1978;64:27-33.

14 Strauss HW, Zaret BL, Hurley PJ, Natarajan TK, Pitt B. A scintiphotographic method for measuring left ventricular ejection fraction in man without cardiac catheterisation. Am J Cardiol 1971;28:575-80.

15 Henry WL, Gardin JM, Ware JH. Echocardiographic measurements in normal subjects from infancy to old age. Circulation 1980;62:1054-61.

16 Crozier IG, Ikram H, Nicholls MG. The pattern of atrial natriuretic peptide release during ventricular tachycardia in man. Clin Exp Pharmacol Physiol 1987;14:597-604.

17 Ellenbogen KA, Rogers R, Walsh M, Mohanty PK. Increased circulating atrial natriuretic factor (ANF) release during induced ventricular tachycardia. Am Heart $J$ 1988;116:1233-8.

18 Fromer M, Razi M, Dubuc M, Bichet D, Shenasa M. Effect of induced ventricular tachycardia on atrial natriuretic

peptide in humans. J Am Coll Cardiol 1988;12:1395-9.
19 Osborn MJ, Hammill SC, Burnett JC. Enhanced levels of circulating atrial natriuretic peptide during ventricular pacing in hum

20 Wood P. Polyuria in paroxysmal tachycardia and paroxysmal atrial flutter and fibrillation. Br Heart $J$ 1963;25: 273-82.

21 Luria MH, Adelson EI, Lochaya S. Paroxysmal tachycardia with polyuria. Ann Intern Med 1966;65:461-70.

22 Benchimol A, Desser KB. Phasic renal artery blood flow velocity in man during cardiac arrhythmias. Am J Med Sci 1971;261:161-6. 